\title{
Health Disparities Between Sexual Minority and Different-Sex-Attracted Adolescents: Quantifying the Intervening Role of Social Support and School Belonging
}

\author{
Francisco Perales, $\mathrm{PhD}$ and Alice Campbell
}

\begin{abstract}
Purpose: An emerging literature documents that sexual minority youth experience significantly and substantially worse health than their heterosexual peers, but few studies have examined the intervening mechanisms linking adolescents' sexual orientation to their health outcomes. This study hypothesized that social support from parents and friends and school belonging would act as important mediators of this relationship and is among the first to test this proposition empirically.

Methods: The analyses used rich data from an Australian national probability sample of 14-15-year olds (Longitudinal Study of Australian Children, $n=3204$ ) and regression models to estimate the associations between sexual attraction and four high-quality indicators of adolescent health/well-being capturing health-related quality of life, socio-emotional functioning, depressive symptoms, and life satisfaction. Mediation tests were subsequently performed to quantify the extent to which three scales capturing social support from parents and friends and school belonging mediated the relationships identified.

Results: Sexual minority status, social support from parents and friends, and school belonging were significantly related to all health/well-being outcomes. Sexual minority adolescents reported significantly lower levels of support and belonging. Collectively, the support and belonging variables were responsible for $49 \%-70 \%$ of the associations between sexual minority status and the health/well-being outcomes, with school belonging being the most important mediator.

Conclusion: These findings have important implications for health equity policy and practice. They suggest that interventions designed to improve the health/well-being of sexual minority adolescents should be directed at eliciting enhanced social support from families and peers and fostering integration at school. School-based interventions may be particularly fruitful.
\end{abstract}

Keywords: health, school, sexual attraction, social support, youth

\section{Introduction}

T HERE IS NOW WIDESPREAD recognition that sexual orientation health disparities have an early onset. For example, U.S. research documents lower levels of substance use and suicidal ideation among heterosexual adolescents than among sexual minority adolescents. ${ }^{1-3}$ Studies in countries such as Australia, ${ }^{4}$ New Zealand, ${ }^{5}$ the United Kingdom, ${ }^{6}$ the Netherlands, ${ }^{7}$ and $\mathrm{Canada}^{8}$ report similar findings. However, fewer contributions have addressed the mechanisms linking adolescent sexual minority status to health. This is an important avenue for further work, as it can point to malleable factors that could be targeted by interventions to improve sexual minority health. ${ }^{9,10}$ Guided by the more-developed literature on sexual orientation health disparities in adult populations ${ }^{10-12}$ and theoretical perspectives on adolescent experiences of minority stress, ${ }^{13,14}$ this study focuses on the potential mediating role of social support and school belonging.

Scholarship that considers the intersections among adolescents' sexual orientation, social relations, and health is emerging rapidly. Most studies examine these processes within targeted samples of sexual minority youth, without a comparison group of heterosexual youth. As such, their findings are useful to understand heterogeneity within sexual minority

Institute for Social Science Research, The University of Queensland, Brisbane, Australia. 
adolescents. This body of research has documented that sexual minority youth who receive greater levels of family/parental support, ${ }^{15-19}$ friend/peer support, ${ }^{18,19}$ community support, ${ }^{18}$ and/or school support ${ }^{19,20}$ report better personal outcomes than sexual minority youth who receive less support. This applies to outcomes such as psychological distress and depressive symptoms ${ }_{15-17,19,20}$ self-esteem, ${ }^{17-19}$ suicidality, ${ }^{17}$ and risk behaviors. ${ }^{17}$ Furthermore, some support types (e.g., peer support) compensate for the absence of others (e.g., family support), buffering lesbian, gay, and bisexual (LGB) youth against suboptimal health outcomes. ${ }^{16}$ It is nevertheless unclear whether or not these associations differ between sexual minority and gender minority/transgender youth, as studies have either aggregated the two groups $s^{15,17,18,20}$ or focused exclusively on LGB youth. ${ }^{16,19}$

Studies examining the role of social relationships in mediating the associations between adolescent sexual orientation and health-that is, health disparities between sexual minority and heterosexual youth-are scarcer. As this is the goal of our study, this body of evidence constitutes the focus of our literature review. The few available studies concentrate on family relations, ${ }^{21,22}$ and such an emphasis is well guided: family relations are pivotal to adolescent adjustment, ${ }^{15}$ and family connectedness and parental support among LGB adolescents have declined over recent years. ${ }^{23}$

Using data from the National Longitudinal Study of Adolescent to Adult Health, Pearson and Wilkinson ${ }^{21}$ showed that parental closeness, family support, and parental involvement significantly mediated the relationship between sexual minority status and depressive symptoms among 7 th-12th graders. Similarly, using data from the NEXT Generation Health Study, Luk et al. ${ }^{22}$ concluded that family satisfaction was a significant mediator of the association between sexual minority status and trajectories of depressive symptoms among young adults aged 17-21 years. Analyses of the Fragile Families and Child Wellbeing study by Mittleman ${ }^{24}$ yielded similar evidence for peer victimization, which was found to mediate the relationship between sexual minority status and depressive/anxious symptoms among 15-year olds. Outside of the United States, Bos et al. ${ }^{25}$ identified a mediating role of relationships with parents, peers, and "class mentors" in the association between sexual minority status and depression within a sample of 13-15-year-old Dutch adolescents. As our focus is on health/well-being status, we do not review studies examining health risk behaviors and suicidality; however, these studies report similar findings. ${ }^{26-28}$

The present study quantifies the mediating role of parental social support, peer social support, and school belonging in the relationship between sexual minority status and several health/well-being indicators. It aims to add to the current evidence base by comparing results from multiple, high-quality measures assessing different domains of health and wellbeing (health-related quality of life, socio-emotional functioning, depressive symptoms, and life satisfaction) and deploying high-quality scale measures for the suspected mediatorsincluding a measure of school belonging, a potential mediator not yet considered in this branch of the literature.

\section{Conceptual framework and research hypotheses}

Intervening factors linking adolescents' sexual minority status to their health outcomes must be differentially distrib- uted among heterosexual and sexual minority youth. As elaborated in the minority stress model, nonheterosexuality remains a stigmatized social status and individuals who identify as a sexual minority often face prejudice, discrimination, and rejection. ${ }^{12,29}$ As a result, sexual minority youth tend to report lower levels of social support than their heterosexual peers. $^{30,31}$ This extends also to parental support, with long-standing evidence that parental rejection of children's nonheterosexuality leads to detached, conflictual, and/or ambivalent parent-child relations. ${ }^{32}$ For youth, schools are a critical and compulsory social environment in which they spend a significant amount of time. Schools are also where the bulk of homophobic bullying against sexual minority youth takes place. ${ }^{33}$ As a result, sexual minority adolescents' perceptions of school belonging have been shown to be weaker than those of heterosexual adolescents. ${ }^{20,34,35}$

Intervening factors linking adolescents' sexual minority status to their health outcomes must also independently influence health. Social support is a key social determinant of health: it enhances the resources available to individuals to combat stressors and mitigates their health manifestations. ${ }^{36}$ Consistent with this, analyses of adolescent samples, specifically, yield positive correlations between receipt of social support and health outcomes. ${ }^{37,38}$ Higher levels of school belonging have also been linked to positive health outcomes among youth - an effect that may operate through emotional connections with school peers and staff, which can buffer health stressors and foster participation in developmental activities. $^{39,40}$

Collectively, the arguments and evidence outlined thus far suggest that social support and school belonging will function as intervening mechanisms in the association between adolescent sexual orientation and adolescent health/well-being. This proposition can be split into a number of testable hypotheses: sexual minority adolescents will report poorer health/well-being $(H 1)$ and lower social support and school belonging (H2) than their different-sexattracted peers, and social support and school belonging will be positively associated with health/well-being outcomes (H3). As a result, social support and school belonging are expected to account for a large share of the observed sexual orientation health disparities (H4). The latter is the central hypothesis in this study.

\section{Methods}

\section{Data}

This research was approved by the Ethics Committee at The University of Queensland and conformed to the principles embodied in the Declaration of Helsinki. The analyses are based on secondary data from the Longitudinal Study of Australian Children (LSAC), a biennial birth-cohort study which has collected information from Australian children since $2004 .{ }^{41}$ The LSAC sample is largely representative of two cohorts of Australian children: one born between March 1999 and February 2000 ("K" cohort) and one born between March 2003 and February 2004 ("B" cohort). A sexual-attraction question was asked of K-cohort children in study wave 6 (ages 14/15 years), collected in late 2014. Our analyses are based on 3204 adolescents with complete data participating in that cohort and study wave. 
Details about LSAC and our analytic subsample are provided in the Supplementary Data.

\section{Sexual orientation}

Information on sexual orientation was collected through a computer-assisted self-interview using the following survey item: Which of these statements best describes your sexual feelings at this time in your life? I'm attracted only to girls, I'm attracted only to boys, I'm attracted to girls and boys, I'm not sure who I am attracted to, I don't feel any attraction to others. When only one domain of sexual orientation can be included in surveys of adolescents, it is best practice to ask about sexual attractions. ${ }^{4,42-45}$ This is because many adolescents may not yet have adopted a sexual minority identity, ${ }^{46,47}$ sexual behavior measures are not relevant to sexually inactive youth ${ }^{48}$ and adolescents perceive sexual attraction as the core dimension of their sexuality. ${ }^{49}$

In this study, we defined sexual minority adolescents as those who indicated that they experienced attractions to members of the same sex or both sexes. Following recent scholarship ${ }^{1,4,14}$ a sexual minority dummy variable was created to distinguish adolescents attracted to members of the same sex, members of the same and different sex, or unsure about their attractions $(n=220 ; 6.87 \%)$. The key contrast was a dummy variable capturing adolescents expressing attraction to members of the different sex only $(n=2855$; $89.11 \%$ ). A category not of analytic interest but included as a control included adolescents expressing no sexual attractions $(n=129 ; 4.03 \%)$.

\section{Health outcomes}

This study considered four high quality health/well-being measures available in LSAC. The first outcome is the Pediatric Quality of Life Inventory (PedsQL) total score - a validated instrument measuring adolescent health-related quality of life (Cronbach's $\alpha=0.92){ }^{50}$ In the PedsQL, parents report how much of a problem for the child 23 items had been during the past month, with possible responses ranging from $0=$ "never a problem" to $4=$ "always a problem." The PedsQL total score was constructed by taking the mean of all items and rescaling it to range from 0 (worst possible outcome) to 100 (best possible outcome).

The second outcome is the Strengths and Difficulties Questionnaire (SDQ) - an adolescent-reported validated instrument capturing adolescents' social, behavioral, and emotional functioning $(\alpha=0.84){ }^{51}$ The 20 items that comprise the SDQ are scored on a 3-point response scale (from $0=$ "not true" to $2=$ "certainly true") and encompass four subscales (conduct problems, emotional problems, peer problems, and hyperactivity and inattention). Scores for all items were summed to create the SDQ total score, which ranges from 0 (best possible outcome) to 40 (worst possible outcome).

The third outcome is the Short Mood and Feelings Questionnaire (SMFQ) - an adolescent-reported validated instrument designed to identify depression $(\alpha=0.94) .{ }^{52}$ For each of the 13 items that comprise the SMFQ, adolescents were asked how much they had felt that way over the past 2 weeks. Responses were measured on a 3-point scale (from $0=$ "not true" to $2=$ "true") and summed to create an over- all score ranging from 0 (best possible outcome) to 26 (worst possible outcome).

The fourth and final outcome is an adolescent-reported single-item measure of overall life satisfaction ("In general, I am happy with how things are for me in my life right now") on a 5-point scale (1="Strongly Disagree"; $5=$ "Strongly Agree").

The SDQ and SMFQ were reverse coded to ensure that higher scores indicated better health/well-being. For comparability, all outcomes were standardized when included in the regression models.

\section{Mediators}

Three factors were evaluated as potential mediators of the association between adolescent sexual attraction and health/ well-being: social support from parents, social support from friends, and school belonging.

Social support was captured using two 8-item, childreported, validated scales of social support from parents $(\alpha=0.94)$ and friends $(\alpha=0.90)$ from the Inventory of Parent and Peer Attachment. ${ }^{53}$ Social support from parents was captured through the child's degree of agreement $(1=$ "almost never or never true"; $4=$ "almost always or always true") with statements such as "My parents accept me," "I share my thoughts and feelings with my parents," or "I trust my parents." The mean of the 8 items was calculated to create an overall score ranging from 1 to 4 , where higher scores denote closer attachment to parents. Social support from friends was captured through the child's degree of agreement ( $1=$ "almost always true"; $5=$ "almost never true") with statements such as "I tell my friends about my problems and troubles," "I feel my friends are good friends," or "I trust my friends." The mean of the 8 items was calculated to create an overall score ranging from 1 to 5 , which was then reverse coded so that higher scores indicate closer attachment to peers.

School belonging was captured using a 12-item version of the Psychological Sense of School Membership scale, a validated instrument capturing the extent to which adolescents feel accepted, respected, included, and supported by others at school. This was based on agreement (1= "not at all true"; $5=$ "completely true") with statements such as "People at this school are friendly to me," "It is hard for people like me to be accepted here," and "I can really be myself at this school" $(\alpha=0.87) .{ }^{54}$ Items were reverse coded as needed and summed to create an overall score (possible range: 12-60), with higher values denoting greater levels of school belonging.

The mediating variables were also standardized for inclusion in regression models.

\section{Control variables}

A set of control variables was included in all regression models to account for potential confounding. These variables resemble those in cognate studies of sexual orientation and adolescent outcomes ${ }^{1,4,14,22}$ and included: sex (male/ female), age (in months), language spoken at home-a proxy for ethno-cultural background (English/other), father's presence (yes/no), mother's presence (yes/no), and number of siblings $(0 / 1 / 2 / 3+)$. Means or percentages and standard deviations (SDs) on all variables (before standardization) are presented in Table 1. 
Table 1. Descriptive Statistics

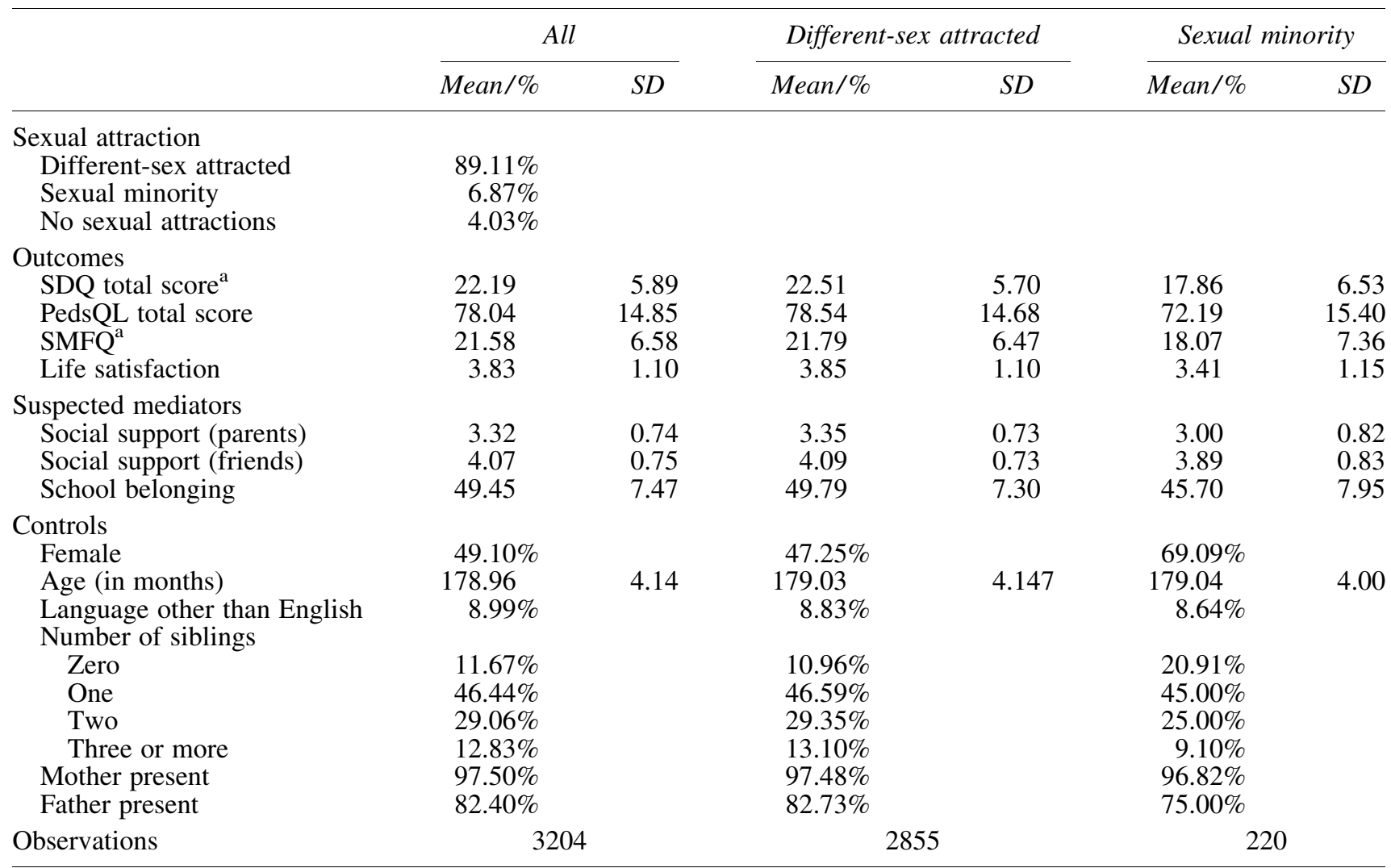

LSAC, K cohort, wave 6 (2014).

${ }^{a}$ Reverse coded.

LSAC, Longitudinal Study of Australian Children; PedsQL, Pediatric Quality of Life Inventory; SD, standard deviation; SDQ, Strengths and Difficulties Questionnaire; SMFQ, Short Mood and Feelings Questionnaire.

\section{Analytic strategy}

Mediation by social support and school belonging in the association between adolescent sexual attraction and health/ well-being outcomes was assessed by applying Baron and Kenny's ${ }^{55}$ approach to the conceptual model presented in Figure 1. Pathways $a, b, c$, and $c$ ' in the diagram were mapped onto the four hypotheses formulated in the conceptual framework. In this framework, mediation occurs when (1) statistically significant associations are observed for pathways $a, b$, and $c$, and (2) the association in pathway $c$ is significantly larger than that in pathway $c$ '. Ordinary least squares (OLS) regression models were used to identify the adjusted associations between sexual minority status and the suspected mediators (pathway $a$ ) and those between the suspected mediators and the health/well-being outcomes (pathway $b$ ). Nested OLS regression models were then fitted to identify pathways $c$ and $c$ ': model 1 included only the

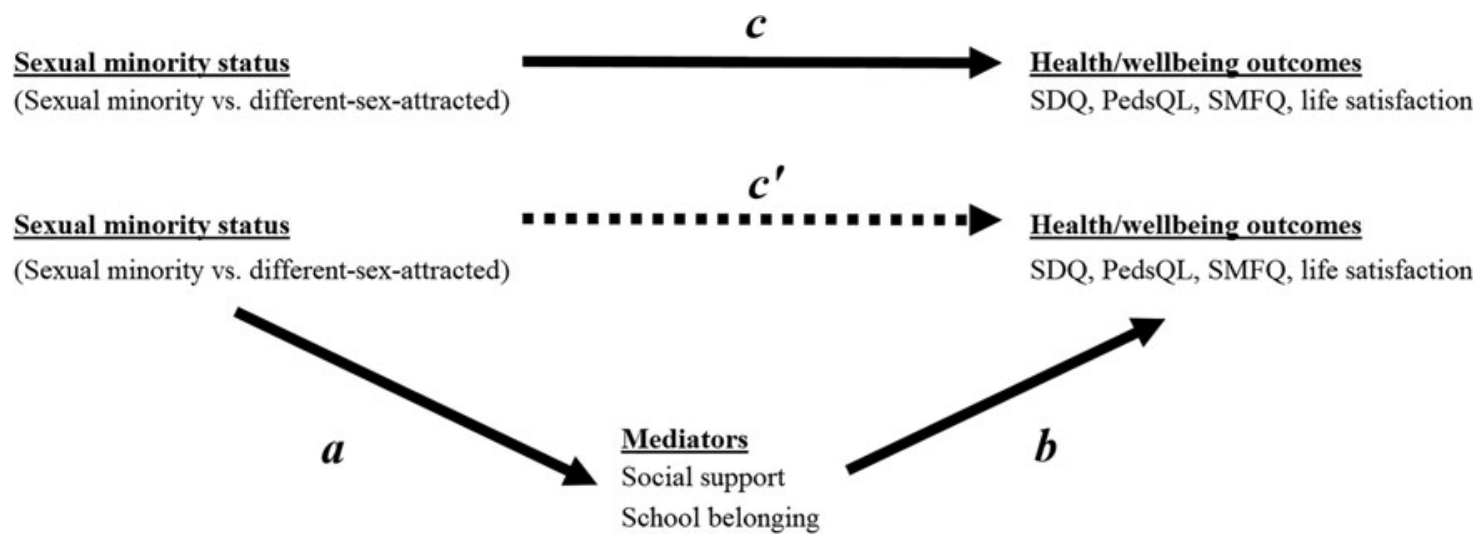

FIG. 1. Conceptual diagram. PedsQL, Pediatric Quality of Life Inventory; SDQ, Strengths and Difficulties Questionnaire; SMFQ, Short Mood and Feelings Questionnaire. 
Table 2. Adjusted Associations Between Sexual Minority Status and Mediators (Pathway a)

\begin{tabular}{lccc}
\hline & $\begin{array}{c}\text { Social support (parents) } \\
\text { Coefficient }(95 \% \text { CI })\end{array}$ & $\begin{array}{c}\text { Social support (friends) } \\
\text { Coefficient (95\% CI) }\end{array}$ & $\begin{array}{c}\text { School belonging } \\
\text { Coefficient (95\% CI) }\end{array}$ \\
\hline Sexual minority & $-0.43 * *$ & $-0.33 * *$ & $-0.50 * *$ \\
$(-0.56$ to -0.29$)$ & $(-0.47$ to -0.20$)$ & $(-0.64$ to -0.37$)$ \\
\hline
\end{tabular}

LSAC, K cohort, wave 6 (2014). $n=3204$. Coefficients from ordinary least squares regression models adjusted for sex, age, Englishspeaking background, number of siblings, father's presence, and mother's presence.

Statistical significance: $* * p<0.01$.

CI, confidence interval.

sexual orientation variables and the controls (pathway $c$ ), whereas models 2-5 added the suspected mediators-one at a time and altogether (pathway $c$ '). The estimated coefficient on the sexual minority dummy variable in model 1 was then formally compared to the same coefficient in models 2-5 using Wald tests.

\section{Results}

Results in Table 2 represent pathway $a$. We hypothesized that sexual minority adolescents would report lower social support and school belonging than their different-sex-attracted peers $(H 2)$. Consistent with this, we found that sexual minority status was negatively and significantly associated with the suspected mediators, net of confounds. The magnitude of the association ranged from 0.33 SDs for social support from friends $(\beta=-0.33 ; p<0.01)$ to $0.50 \mathrm{SDs}$ for school belonging $(\beta=-0.50 ; p<0.01)$.

Results in Table 3 represent pathway $b$. In $H 3$, we hypothesized that social support and school belonging would be positively associated with health/well-being. Consistent with this, we found that all forms of support were related to better adolescent health/well-being, net of confounds. A SD increase in parental social support was associated with health/ well-being improvements ranging from 0.21 SDs (PedsQL: $\beta=0.21 ; p<0.01$ ) to 0.44 SDs (SDQ: $\beta=0.44 ; p<0.01$ ). Similarly, a SD increase in social support from friends improved health/well-being by 0.17 SDs (PedsQL: $\beta=0.17 ; p<0.01$ ) to 0.38 SDs (SDQ: $\beta=0.38 ; p<0.01$ ). For school belonging, the analogous effect range was 0.32 SDs (PedsQL: $\beta=0.32$; $p<0.01$ ) to 0.64 SDs (SDQ: $\beta=0.64 ; p<0.01$ ).

Table 4 presents the results of nested models of pathways $c$ and $c$ '. We hypothesized that sexual minority adolescents would report poorer health/well-being than their differentsex-attracted peers $(\mathrm{Hl})$ and that social support and school belonging would mediate this association (H4). Consistent with
$H 1$, sexual minority status was negatively and significantly associated with all health/well-being outcomes, net of confounds and before including the mediators (model 1; pathway $c$ ). That is, sexual minority adolescents experienced worse health/wellbeing than different-sex-attracted adolescents across all four domains. These health differences amounted to 0.70 SDs for the SDQ $(\beta=-0.70 ; p<0.01), 0.47$ SDs for the SMFQ $(\beta=-0.47 ; p<0.01), 0.37$ SDs for life satisfaction $(\beta=-0.37$; $p<0.01)$, and 0.35 SDs for the PedsQL $(\beta=-0.35 ; p<0.01)$.

Consistent with $\mathrm{H} 4$, the estimated associations between sexual minority status and health/well-being were however substantially smaller in the model including all mediators (model 5; pathway $c^{\prime}$ ): 0.35 SDs for the SDQ $(\beta=-0.35$; $p<0.01), 0.20$ SDs for the SMFQ $(\beta=-0.20 ; p<0.01)$, 0.18 SDs for the PedsQL $(\beta=-0.18 ; p<0.01)$, and 0.11 SDs for life satisfaction $(\beta=-0.11 ; p>0.05)$. The coefficient on sexual minority status in the life satisfaction model was no longer statistically significant. As shown in Table 5, reductions in the magnitude of the sexual minority coefficient between models 1 and 5 ranged between $70 \%$ (life satisfaction) and $49 \%$ (PedsQL) and were in all cases statistically significant $(p<0.05)$.

The results of models 2 to 4 in Tables 4 and 5 provide insights about which of these factors has a stronger mediating effect. School belonging had the most pronounced effect: reductions in the magnitude of the sexual minority coefficient were largest in models including the school belonging index (45\%-59\%). The second strongest mediation effect was for parental social support $(24 \%-40 \%)$ and the weakest for social support from friends $(15 \%-24 \%)$. For the latter, mediation effects were not statistically significant $(p>0.1)$.

\section{Discussion}

Consistent with our first hypothesis $(H 1)$ and with tenets of the minority stress model, Australian sexual minority

Table 3. Adjusted Associations Between Mediators and Health/Well-being Outcomes (Pathway B)

\begin{tabular}{|c|c|c|c|c|}
\hline & $\begin{array}{c}S D Q \\
\text { Coefficient }(95 \% \text { CI) }\end{array}$ & $\begin{array}{c}\text { Peds } Q L \\
\text { Coefficient }(95 \% \mathrm{CI})\end{array}$ & $\begin{array}{c}\text { SMFQ } \\
\text { Coefficient }(95 \% \text { CI) }\end{array}$ & $\begin{array}{c}\text { Life satisfaction } \\
\text { Coefficient }(95 \% \text { CI })\end{array}$ \\
\hline $\begin{array}{l}\text { Panel 1: Social support } \\
\text { (parents) }\end{array}$ & $0.44 * *(0.41$ to 0.47$)$ & $0.21 * *(0.17$ to 0.24$)$ & $0.36 * *(0.33$ to 0.40$)$ & $0.35^{* *}(0.32$ to 0.38$)$ \\
\hline $\begin{array}{l}\text { Panel 2: Social support } \\
\text { (friends) }\end{array}$ & $0.38 * *(0.35$ to 0.42$)$ & $0.17 * *(0.13$ to 0.20$)$ & $0.26 * *(0.23$ to 0.30$)$ & $0.27 * *(0.24$ to 0.31$)$ \\
\hline Panel 3: School belonging & $0.64 * *(0.61$ to 0.67$)$ & $0.32 * *(0.29$ to 0.35$)$ & $0.46^{* *}(0.43$ to 0.49$)$ & $0.44 * *(0.41$ to 0.47$)$ \\
\hline
\end{tabular}

LSAC, K cohort, wave 6 (2014). $n=3204$. Coefficients from ordinary least squares regression models adjusted for sex, age, Englishspeaking background, number of siblings, father's presence, and mother's presence.

Statistical significance: $* * p<0.01$. 


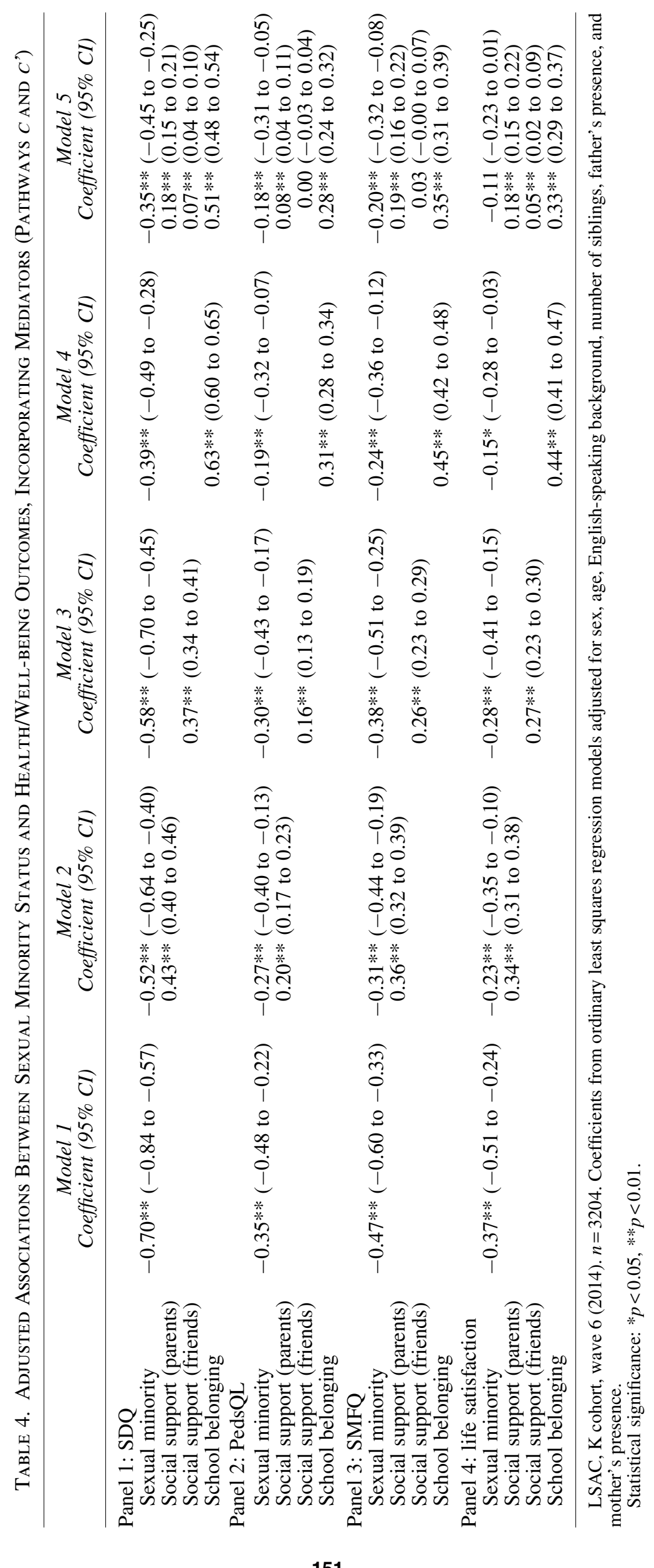


Table 5. Comparison of Sexual Minority Coefficients Across Models

\begin{tabular}{|c|c|c|c|c|c|c|c|c|}
\hline & \multicolumn{2}{|c|}{$\begin{array}{l}\text { Model } 2 \text { vs. model } 1 \\
\text { (parental } \\
\text { social support) }\end{array}$} & \multicolumn{2}{|c|}{$\begin{array}{l}\text { Model } 3 \text { vs. model } 1 \\
\text { (social support } \\
\text { from friends) }\end{array}$} & \multicolumn{2}{|c|}{$\begin{array}{l}\text { Model } 4 \text { vs. model } 1 \\
\text { (school belonging) }\end{array}$} & \multicolumn{2}{|c|}{$\begin{array}{l}\text { Model } 5 \text { vs. model } 1 \\
\text { (all mediators) }\end{array}$} \\
\hline & $\begin{array}{l}\% \text { difference } \\
\text { in coefficient }\end{array}$ & $\begin{array}{l}\mathrm{p} \text { value of } \\
\text { difference }\end{array}$ & $\begin{array}{l}\% \text { difference } \\
\text { in coefficient }\end{array}$ & $\begin{array}{l}\mathrm{p} \text { value of } \\
\text { difference }\end{array}$ & $\begin{array}{l}\% \text { difference } \\
\text { in coefficient }\end{array}$ & $\begin{array}{l}\mathrm{p} \text { value of } \\
\text { difference }\end{array}$ & $\begin{array}{l}\% \text { difference } \\
\text { in coefficient }\end{array}$ & $\begin{array}{l}\mathrm{p} \text { value of } \\
\text { difference }\end{array}$ \\
\hline Panel 1: SDQ & 26.01 & 0.023 & 17.78 & 0.088 & 44.79 & $<0.001$ & 50.70 & $<0.001$ \\
\hline Panel 2: PedsQL & 24.37 & 0.185 & 15.27 & 0.288 & 44.64 & 0.048 & 48.95 & 0.034 \\
\hline Panel 3: SMFQ & 32.56 & 0.053 & 18.62 & 0.181 & 48.53 & 0.007 & 57.18 & 0.002 \\
\hline $\begin{array}{l}\text { Panel 4: life } \\
\text { satisfaction }\end{array}$ & 39.52 & 0.062 & 24.15 & 0.177 & 59.08 & 0.010 & 69.98 & 0.003 \\
\hline
\end{tabular}

Based on results presented in Table 4. "\% difference" calculated as $\left[\left(\beta_{\text {Model 1 }}-\beta_{\text {Model 2) }} \beta_{\text {Model 1 }}\right) \times 100\right]$. " $p$ value of difference" is the $p$ value from a one-sided Wald test.

adolescents experienced poorer health-related quality of life and socio-emotional functioning, more depressive symptoms, and lower life satisfaction than their different-sex-attracted counterparts. This pattern of results and the magnitude of the estimated effects (0.35-0.70 SDs) are consistent with earlier international $^{6,7}$ and Australian ${ }^{4}$ evidence. Also consistent with expectations $(H 2)$ and the minority stress framework, sexual minority adolescents reported significantly and substantially lower levels of social support from parents and friends and school belonging - in the range of 0.33-0.50 SDs. These are comparable to estimates reported in earlier scholarship from the United States, ${ }^{31,34}$ the Netherlands, ${ }^{25}$ and New Zealand. ${ }^{5}$ Consistent with the third hypothesis (H3), our Australian analyses also underscored the importance of social support and school belonging for adolescent health ${ }^{38-40}$ : one-SD increases in these measures were associated with increases of $0.17-$ 0.64 SDs in the health/well-being outcomes.

Altogether, these results suggested that social support and school belonging would mediate the relationship between adolescent sexual minority status and health/well-being. The subsequent analyses are among the first to provide empirical evidence in support of this point. Consistent with the last and main hypothesis (H4), social support from parents and friends and school belonging were collectively responsible for $49 \%-70 \%$ of the association between sexual minority status and health outcomes. The explanatory power of these different support sources in the models was slightly larger than that attributed to family and peer support in earlier United States and Canadian research on various mental health outcomes ${ }^{22-24}$ and to relationships with parents, peers, and "class mentors" in earlier research on depression using a Dutch sample. ${ }^{25}$

School belonging played the strongest mediating role in the association between adolescent sexual minority status and health/well-being, suggesting that integration of sexual minority adolescents within schools is critical to closing health disparities. This finding is noteworthy, as earlier studies comparing the outcomes of sexual minority and heterosexual/ different-sex-attracted youth had focused on support from family and friends, ${ }^{21,22,25}$ but had not considered school belonging. It is nevertheless consistent with results from previous analyses of sexual minority subsamples. For example, Hatchel et al. ${ }^{20}$ found that school belonging was an important mediator of the relationship between victimization and depression among lesbian, gay, bisexual, transgender, and questioning youth. Our finding may reflect that-within this generation of Australian teens-parents generally support their nonhetero- sexual children, and these children have access to networks of supportive peers. However, schools are heteronormative social environments that remain "compulsory" for sexual minority adolescents and represent contexts where these adolescents have little choice to decide with whom they interact. ${ }^{13,14}$ Furthermore-unlike countries such as the United StatesAustralia lacks school-based programs aimed at reducing stigma and bullying toward sexual minority youth. ${ }^{9}$

\section{Study strengths and limitations}

This study had a number of strengths: it relied on a national probability sample; it leveraged high-quality measures of sexual orientation, health/well-being, social support, and school belonging; and it considered a new country context (Australia).

Study limitations included the absence of objectively measured health outcomes, lack of information on domains of adolescent sexual orientation other than sexual attraction (i.e., sexual identity and behavior), and a relatively modest subsample of sexual minority adolescents $(n=220)$. The latter precluded us from stratifying the analyses by sex or undertaking comparisons between different sexual minority categories (i.e., same-sex attracted, both-sex attracted, and "unsure" adolescents). In addition, the available data were cross-sectional, and longitudinal data would have been better suited to assess the mediation processes of interest.

The scope of our analyses was also restricted by having no information on the degree to which sexual minority adolescents were "out" about their identity and/or attractions to different social partners (e.g., parents, peers) and in different social contexts (e.g., at school, at home) or about their perceived degree of acceptance of their sexuality. Although this does not affect our main conclusions, it is likely that these factors moderate the relationships under consideration-for example, the importance of family/school support for health disparities may differ between sexual minority youth who are out and those who are not out. Studies of representative samples that account for moderation by these and other factors are required.

\section{Conclusion}

Our findings suggest that interventions designed to improve the health/well-being of sexual minority adolescents should be directed at eliciting enhanced social support from families and peers and fostering integration at school. Examples of support-based interventions to eradicate sexual 
minority disadvantage have been discussed in the literatureincluding attachment-based family therapy, the establishment of Gay-Straight Alliances in schools, and educational programs aimed at parents and school staff. ${ }^{9}$ The results suggest that school-based interventions may be particularly fruitful. However, the findings also indicate that equalizing support to sexual minority adolescents from parents, peers, and schools is not sufficient to fully close outcome gaps. This highlights the importance of further identifying other mechanisms contributing to the health/well-being disadvantage experienced by nonheterosexual adolescents.

\section{Disclaimer}

This article uses data from the Longitudinal Study of Australian Children, a survey conducted in partnership among the Department of Social Services, the Australian Institute of Family Studies, and the Australian Bureau of Statistics.

\section{Author Disclosure Statement}

No competing financial interests exist.

\section{Funding Information}

This research was supported by an Australian Research Council Discovery Early Career Researcher Award to Francisco Perales for a project titled "Sexual Orientation and Life Chances in Contemporary Australia."

\section{Supplementary Material}

Supplementary Data

\section{References}

1. Caputi TL, Smith LR, Strathdee SA, Ayers JW: Substance use among lesbian, gay, bisexual, and questioning adolescents in the United States, 2015. Am J Public Health 2018;108:1031-1034.

2. Stone DM, Luo F, Ouyang L, et al.: Sexual orientation and suicide ideation, plans, attempts, and medically serious attempts: Evidence from local Youth Risk Behavior Surveys, 2001-2009. Am J Public Health 2014;104:262-271.

3. Kidd JD, Jackman KB, Wolff M, et al.: Risk and protective factors for substance use among sexual and gender minority youth: A scoping review. Curr Addict Rep 2018;5:158-173.

4. Perales F, Campbell A: Early roots of sexual-orientation health disparities: Associations between sexual attraction, health and well-being in a national sample of Australian adolescents. J Epidemiol Community Health 2019;73:954-962.

5. Lucassen MF, Clark TC, Denny SJ, et al.: What has changed from 2001 to 2012 for sexual minority youth in New Zealand? J Paediatr Child Health 2015;51:410-418.

6. Irish M, Solmi F, Mars B, et al.: Depression and self-harm from adolescence to young adulthood in sexual minorities compared with heterosexuals in the UK: A populationbased cohort study. Lancet Child Adolesc Health 2019;3: 91-98.

7. Kuyper L, de Roos S, Iedema J, Stevens G: Growing up with the right to marry: Sexual attraction, substance use, and well-being of Dutch adolescents. J Adolesc Health 2016; 59:276-282.

8. Watson RJ, Peter T, McKay T, et al.: Evidence of changing patterns in mental health and depressive symptoms for sex- ual minority adolescents. J Gay Lesbian Ment Health 2018; 22:120-138.

9. Chaudoir SR, Wang K, Pachankis JE: What reduces sexual minority stress? A review of the intervention "toolkit." J Soc Issues 2017;73:586-617.

10. Perales F, Todd A: Structural stigma and the health and wellbeing of Australian LGB populations: Exploiting geographic variation in the results of the 2017 same-sex marriage plebiscite. Soc Sci Med 2018;208:190-199.

11. Hatzenbuehler ML: How does sexual minority stigma "get under the skin"? A psychological mediation framework. Psychol Bull 2009;135:707-730.

12. Meyer IH: Prejudice, social stress, and mental health in lesbian, gay, and bisexual populations: Conceptual issues and research evidence. Psychol Bull 2003;129:674-697.

13. Goldbach JT, Gibbs JJ: A developmentally informed adaptation of minority stress for sexual minority adolescents. J Adolesc 2017;55:36-50.

14. Perales F, Campbell A, O'Flaherty M: Sexual orientation and adolescent time use: How sexual minority youth spend their time. Child Dev 2019 [Epub ahead of print]; DOI:10.1111/cdev.13245.

15. McConnell EA, Birkett M, Mustanski B: Families matter: Social support and mental health trajectories among lesbian, gay, bisexual, and transgender youth. J Adolesc Health 2016; 59:674-680.

16. Parra LA, Bell TS, Benibgui M, et al.: The buffering effect of peer support on the links between family rejection and psychosocial adjustment in LGB emerging adults. J Soc Pers Relat 2018;35:854-871.

17. Ryan C, Russell ST, Huebner D, et al.: Family acceptance in adolescence and the health of LGBT young adults. J Child Adolesc Psychiatr Nurs 2010;23:205-213.

18. Snapp SD, Watson RJ, Russell ST, et al.: Social support networks for LGBT young adults: Low cost strategies for positive adjustment. Fam Relat 2015;64:420-430.

19. Watson RJ, Grossman AH, Russell ST: Sources of social support and mental health among LGB youth. Youth Soc 2019;51:30-48.

20. Hatchel T, Espelage DL, Huang Y: Sexual harassment victimization, school belonging, and depressive symptoms among LGBTQ adolescents: Temporal insights. Am J Orthopsychiatry 2018;88:422-430.

21. Pearson J, Wilkinson L: Family relationships and adolescent well-being: Are families equally protective for same-sex attracted youth? J Youth Adolesc 2013;42:376-393.

22. Luk JW, Gilman SE, Haynie DL, Simons-Morton BG: Sexual orientation and depressive symptoms in adolescents. Pediatrics 2018;141:1-10.

23. Watson RJ, Rose HA, Doull M, et al.: Worsening perceptions of family connectedness and parent support for lesbian, gay, and bisexual adolescents. J Child Fam Stud 2019;28:3121-3131.

24. Mittleman J: Sexual minority bullying and mental health from early childhood through adolescence. J Adolesc Health 2019;64:172-178.

25. Bos HM, Sandfort TG, de Bruyn EH, Hakvoort EM: Samesex attraction, social relationships, psychosocial functioning, and school performance in early adolescence. Dev Psychol 2008;44:59-68.

26. Eisenberg ME, Resnick MD: Suicidality among gay, lesbian and bisexual youth: The role of protective factors. J Adolesc Health 2006;39:662-668.

27. Robinson JP, Espelage DL: Peer victimization and sexual risk differences between lesbian, gay, bisexual, transgender, 
or questioning and nontransgender heterosexual youths in grades 7-12. Am J Public Health 2013;103:1810-1819.

28. Toomey RB, Syvertsen AK, Flores M: Are developmental assets protective against suicidal behavior? Differential associations by sexual orientation. J Youth Adolesc 2019; 48:788-801.

29. Fredriksen-Goldsen KI, Simoni JM, Kim HJ, et al.: The health equity promotion model: Reconceptualization of lesbian, gay, bisexual, and transgender (LGBT) health disparities. Am J Orthopsychiatry 2014;84:653-663.

30. Johns MM, Zimmerman M, Bauermeister JA: Sexual attraction, sexual identity, and psychosocial wellbeing in a national sample of young women during emerging adulthood. J Youth Adolesc 2013;42:82-95.

31. Ueno K: Sexual orientation and psychological distress in adolescence: Examining interpersonal stressors and social support processes. Soc Psychol Q 2005;68:258-277.

32. Peplau LA, Fingerhut AW: The close relationships of lesbians and gay men. Annu Rev Psychol 2007;58:405-424.

33. Toomey RB, Russell ST: The role of sexual orientation in school-based victimization: A meta-analysis. Youth Soc 2016;48:176-201.

34. Galliher RV, Rostosky SS, Hughes HK: School belonging, self-esteem, and depressive symptoms in adolescents: An examination of sex, sexual attraction status, and urbanicity. J Youth Adolesc 2004;33:235-245.

35. Espelage DL, Aragon SR, Birkett M, Koenig BW: Homophobic teasing, psychological outcomes, and sexual orientation among high school students: What influence do parents and schools have? School Psych Rev 2008;37:202-216.

36. Wilkinson RG, Marmot M (Editors): Social Determinants of Health: The Solid Facts. Copenhagen, Denmark: World Health Organization Regional Office for Europe, 2003.

37. Eisman AB, Stoddard SA, Heinze J, et al.: Depressive symptoms, social support, and violence exposure among urban youth: A longitudinal study of resilience. Dev Psychol 2015;51:1307-1316.

38. Gecková A, van Dijk JP, Stewart R, et al.: Influence of social support on health among gender and socio-economic groups of adolescents. Eur J Public Health 2003;13:44-50.

39. Bond L, Butler H, Thomas L, et al.: Social and school connectedness in early secondary school as predictors of late teenage substance use, mental health, and academic outcomes. J Adolesc Health 2007;40:357.e9-357.e18.

40. Kidger J, Araya R, Donovan J, Gunnell D: The effect of the school environment on the emotional health of adolescents: A systematic review. Pediatrics 2012;129:925-949.

41. Australian Institute of Family Studies: The Longitudinal Study of Australian Children: An Australian Government Initiative. Data User Guide-December 2018. Melbourne, Australia: Australian Institute of Family Studies, 2018.

42. Austin SB, Conron KJ, Patel A, Freedner N: Making sense of sexual orientation measures: Findings from a cognitive processing study with adolescents on health survey questions. J LGBT Health Res 2007;3:55-65.

43. Sexual Minority Assessment Research Team (SMART): Best Practices for Asking Questions about Sexual Orientation on Surveys. Los Angeles, CA: The Williams Institute, 2009.
44. Durso LE, Gates GJ: Best practices: Collecting and analyzing data on sexual minorities. In: International Handbook on the Demography of Sexuality. Edited by Baumle AK. Dordrecht: Springer, 2013, pp 21-42.

45. Wolff M, Wells B, Ventura-DiPersia C, et al.: Measuring sexual orientation: A review and critique of US data collection efforts and implications for health policy. J Sex Res 2017;54:507-531.

46. Katz-Wise SL, Rosario M, Calzo JP, et al.: Endorsement and timing of sexual orientation developmental milestones among sexual minority young adults in the Growing Up Today Study. J Sex Res 2017;54:172-185.

47. Savin-Williams RC, Cohen KM: Developmental trajectories and milestones of lesbian, gay, and bisexual young people. Int Rev Psychiatry 2015;27:357-366.

48. Saewyc EM, Bauer GR, Skay CL, et al.: Measuring sexual orientation in adolescent health surveys: Evaluation of eight school-based surveys. J Adolesc Health 2004;35: 345.e1-345.e15.

49. Friedman MS, Silvestre AJ, Gold MA, et al.: Adolescents define sexual orientation and suggest ways to measure it. J Adolesc 2004;27:303-317.

50. Varni JW, Seid M, Kurtin PS: PedsQL ${ }^{\mathrm{TM}}$ 4.0: Reliability and validity of the Pediatric Quality of Life Inventory ${ }^{\mathrm{TM}}$ version 4.0 generic core scales in healthy and patient populations. Med Care 2001;39:800-812.

51. Goodman R: The Strengths and Difficulties Questionnaire: A research note. J Child Psychol Psychiatry 1997;38:581586.

52. Angold A, Costello EJ, Messer SC, Pickles A: Development of a short questionnaire for use in epidemiological studies of depression in children and adolescents. Int J Methods Psychiatr Res 1995;5:237-249.

53. Armsden GC, Greenberg MT: The inventory of parent and peer attachment: Individual differences and their relationship to psychological well-being in adolescence. J Youth Adolesc 1987;16:427-454.

54. Goodenow C: The Psychological Sense of School Membership among adolescents: Scale development and educational correlates. Psychol Sch 1993;30:79-90.

55. Baron RM, Kenny DA: The moderator-mediator variable distinction in social psychological research: Conceptual, strategic, and statistical considerations. J Pers Soc Psychol 1986;51:1173-1182.

Address correspondence to: Francisco Perales, PhD Institute for Social Science Research The University of Queensland Long Pocket Precinct 80 Meiers Road Indooroopilly Brisbane, QLD 4068 Australia

E-mail: f.perales@uq.edu.au 